\title{
ИЗУЧЕНИЕ АТМОСФЕРНОГО ЗАГРЯЗНЕНИЯ БОТАНИЧЕСКОГО САДА НАН УКРАИНЫ МЕТОДОМ ТЕСТОВЫХ ТРАНСПЛАНТАТОВ О.Б. БЛюм ${ }^{1}$ Ю.Г. Тютюнник ${ }^{2 *}$ \\ ${ }^{1}$ Национальный ботанический сад им. Н.Н. Гришко НАН Украины; \\ ${ }^{2}$ Институт эволюционной биологии НАН Украины, Киев, Украина \\ * Эл.nочma: carme1@mail.ru \\ Статья поступила в редакиию 14.07.2016; принята к печати 27.07.2016
}

Представлены результаты экспериментального изучения загрязнения приземного слоя воздуха на территории Национального ботанического сада НАН Украины (г. Киев) методом тестовых трансплантатов. В качестве организма-трансплантата использовался эпифитный лишайник Hypogymnia physodes (L.) Nyl. B слоевищах трансплантатов разных сроков экспозиции (холодное и теплое полугодие, год, полтора года) методом плазменной эмиссионной спектроскопии определялись химические элементы Са, K, P, S, Mg, Al, Fe, Mn, Na, $\mathrm{Zn}, \mathrm{Sr}, \mathrm{Ba}, \mathrm{Ti}, \mathrm{Cu}, \mathrm{Pb}, \mathrm{Cr}, \mathrm{Ni}, \mathrm{V}, \mathrm{Cd}, \mathrm{Co}$, Sb. Рассчитаны коэффициенты концентрирования и рассеивания химических элементов в тканях лишайников в разные периоды экспонирования. На основании интерпретации этих коэффициентов были выявлены и охарактеризованы основные временные и пространственные закономерности атмосферного загрязнения экосистем ботанического сада.

Ключевые слова: загрязнение воздуха, миграция поллютантов, экологический мониторинг, биогеохимическая лихеноиндикация, тестовая трансплантация.

\section{USING TEST TRANSPLANTS TO STUDY AIR POLLUTION IN THE BOTANIC GARDEN OF THE NATIONAL ACADEMY OF SCIENCES OF UKRAINE O.B. Blum ${ }^{1}$, Yu.G. Tyutyunnik ${ }^{2}$, \\ ${ }^{1}$ N.N. Grishko National Botanical Garden of the National Academy of Sciences of Ukraine; ${ }^{2}$ Institute of Evolutionary Ecology of the National Academy of Sciences of Ukraine, Kiev; Ukraine E-mail:carme1@mail.ru}

To study ground air pollution in the Botanical Garden of the National Academy of Sciences of Ukraine (Kiev), the epiphytic lichen Hypogymnia physodes (L.) Nyl. was used as a test transplant. Thallus specimens of the transplants exposed to ambient air during different periods under different conditions (cold or warm half-year, one year, or one year and a half) were isolated. Plasma emission spectroscopy was used to determine the contents of the chemical elements $\mathrm{Ca}, \mathrm{K}, \mathrm{P}, \mathrm{S}, \mathrm{Mg}, \mathrm{Al}, \mathrm{Fe}, \mathrm{Mn}, \mathrm{Na}, \mathrm{Zn}, \mathrm{Sr}, \mathrm{Ba}, \mathrm{Ti}, \mathrm{Cu}, \mathrm{Pb}, \mathrm{Cr}, \mathrm{Ni}, \mathrm{V}, \mathrm{Cd}, \mathrm{Co}$, and $\mathrm{Sb}$ in the specimens. Concentration and scattering coefficients of the elements in the specimens were calculated for different conditions and periods of exposure. Calculation results were interpreted to characterize the main temporal and spatial patterns of air pollution in the ecosystem of the botanical garden.

Keywords: air pollution, migration of pollutants, environmental monitoring, biogeochemical lichenoindication transplant test.

\section{Введение}

Изучение атмосферного загрязнения с помощью пересадки (трансплантации) растений из чистых (фоновых) местообитаний на территории, подверженные техногенному влиянию, является эффективным и популярным сегодня методом пассивного биомониторинга. Он базируется на общих законах биогеохимии растений [3]. Растение-трансплантат, перенесенное из фонового местообитания в загрязненное, накапливает химические вещества и элементы техногенного происхождения до тех пор, пока между их содержанием в растительном организме и окружающей среде (воздухе, воде, почвах) не установится динамическое равновесие. Уровни накопления химических элементов растением характеризуются коэффициентом концентрирования $\left(K_{\kappa}\right)$, который рассчитывается как отношение концентрации химического элемента в слоевище лишайника-трансплантата после срока экспонирования и содержания этого химического элемента в исходном (фоновом) материале, использовавшемся для экспонирования. Этот коэффициент по своему геохимическому смыслу аналогичен введенному в геохимию А.Е. Ферсманом в 1933 г. показателю степени концентрации элемента; позже его стали называть коэффициентом концентрации. Он показывает, насколько сильно химический элемент концентрируется в том или ином геохимическом объекте в аномальной обстановке по сравнению с фоном. Если аномальная геохимическая обстановка обусловливается атмосферным загрязнением, то $K_{\kappa}$ становится близким по смыслу к используемому в геохимии техногенеза коэффициенту относительного увеличения общей нагрузки элемента [1].

Однако, как свидетельствуют многочисленные данные разных исследователей, в условиях усиления техногенной нагрузки на растения происходит не только увеличение содержания в них химических элементов, но и уменьшение некоторых из них. Это касается, прежде всего, биогенных элементов, в особенности калия и фосфора [5]. Причина проста. Эти элементы участвуют в физиологических процессах, a последние в условиях техногенного пресса (не толь- 
ко загрязнения, но и иссушения, ухудшения инсоляции и других причин) в растительных организмах угнетаются. В результате снижается интенсивность поглощения физиологически активных химических элементов - K, P, Cu, Zn и др., даже если некоторые из них являются важными загрязнителями окружающей среды и их содержание в ней превышает фоновое в несколько раз. В этом случае приходится говорить уже не о коэффициенте концентрирования, а о коэффициенте рассеивания $\left(K_{p}\right)$. Фактором, обусловливающим снижение содержания химического элемента в растительном организме в техногенных условиях в сравнении с фоном, может выступать также воздействие кислых осадков на его ткани (обычное явление на территориях с сильной техногенной нагрузкой). В кислой среде мобилизуется и вымывается из растительных тканей целый ряд химических элементов, особенно с переменной валентностью. Коэффициенты рассеивания также могут служить показателем техногенного «пресса», но менее информативным, чем коэффициенты концентрирования, из-за того, что сложно количественно оценить причины, обусловливающие, с одной стороны, повышенное поступление химического элемента в условиях загрязнения, а с другой - их же усиленную десорбцию из растительных тканей.

Механизмы поглощения химических элементов лишайниками до конца не изучены, но в целом считается, что они, поступая в таллом из воздуха в форме пыле-аэрозолей и в составе растворов атмосферной влаги (осадки, гидрометеоры, туман), закрепляются в организме лишайника тремя основными способами: 1) адсорбция на поверхности слоевища и абсорбция в межклеточном пространстве; 2) связывание с обменными центрами на поверхности клеточных стенок грибов и водорослей, образующих организм лишайника (так называемое внеклеточное поглощение); 3) проникновение в клетки (внутриклеточное поглощение) $[6,8]$. Ведущую роль играют первые два механизма поглощения химических элементов лишайниками. Учет механизмов преимущественного поглощения, а также десорбции для разных химических элементов является важным при интерпретации данных трансплантационных опытов.

Для определения уровней загрязнения атмосферного воздуха необходимо использовать такие растения, которые в наименьшей мере поглощают химические элементы и вещества из твердого субстрата, на котором произрастают, а в наибольшей степени - из воздушной среды. Лихенологами уже давно доказано, что такими растениями являются эпифитные кустистые, а также листоватые лишайники. Их чаще всего и используют при определении загрязнения атмосферного воздуха методом трансплантации [2]. Соответствующие методики разработаны и известны [4, 9]. Одним из наиболее популярных и практически доступных для трансплантации листоватых эпифитных лишайников северной бореальной зоны является Hypogymnia physodes (L.) Nyl. [4, 7, 10, 11]. Он широко распространен в разных биотопах и сравнительно устойчив к условиям техногенного загрязнения.

\section{Материалы и методы}

Сбор лишайника. Образцы лишайника $H$. physodes для трансплантации в Национальном ботаническом саду им. Н.Н. Гришко Национальной академии наук
Украины (далее НБС НАНУ или НБС) отбирались в молодом сосновом лесу на северо-западе Иванковского района Киевской области, примерно в 7 км на юго-восток от деревни Кухари и юго-запад от села Яхнивка. Лишайник отбирался вместе с веточками деревьев, на которых рос, на высоте 0,5-1,5 м от земной поверхности. Диаметр веточек - 0,5-1,5 см, длина - 15-20 см. Сбор образцов для трансплантации осуществлялся в ясную и солнечную погоду, державшуюся несколько дней перед отбором, поэтому отобранные розетки были вполне сухими. После срезания веточки сразу запаковывали в чистые бумажные, а сверху в полиэтиленовые обертки и помещались в картонные коробки. Тем самым прекращался свободный доступ воздуха к отобранному материалу. Отбор биоматериала для трансплантации проводился дважды - в конце апреля (материал первого отбора) и в конце октября (материал второго отбора) 2013 г.

Способы и сроки высадки (экспонирования) образизов лишайника. Собранные лишайники высаживались в места экспонирования через 1-2 дня после сбора на фоновых территориях. Веточки с розетками гипогимний в количестве двух-трех штук привязывались капроновым шнуром на деревянные штапики квадратного сечения $1 \times 1$ см и общей длиной около 28 см. Штапики с веточками трансплантантов на высоте 1,5-2,5 м от комля крепились под углом $65-70^{\circ}$ до ствола с таким расчетом, чтобы на розетки лишайников не попадал сток, образующийся на стволах во время дождя и снеготаяния. Один штапик с двумя-тремя веточками считался одним трансплантатом. Общее число розеток лишайника на каждом трансплантате варьировало в пределах 9-13 штук (в зависимости от размеров веточек и розеток).

В выбранных для трансплантации пунктах экспозиции образцы лишайников высаживались на разные временные периоды, а именно: с 28 апреля 2013 г. по 28 октября 2013 г. (полугодичная экспозиция в теплый период года - «0,5m»); с 28 октября 2013 г. по 28 апреля 2014 г. (полугодичная экспозиция в холодный период года - «0,5x»); с 28 апреля 2013 г. по 28 апреля 2014 г. (годичная экспозиция - «1»); с 28 апреля 2013 г. по 28 октября 2014 г. (полуторагодичная экспозиция - «1,5»). Фоновый материал для трансплантации на периоды $0,5 m, 1$ и 1,5 , с одной стороны, и на высадку с периодом $0,5 x$, с другой, отбирался по отдельности. К сожалению, во время длительных экспозиций не удалось воспрепятствовать порче некоторых высаженных образцов по независимым от нас техническим причинам. Это обусловило пробелы при получении окончательных результатов эксперимента.

Пункты высадки трансплантатов на территории НБС выбирались с учетом следующего в порядке убывания степени важности: а) миграция атмосферных выбросов промзоны «Выдубечи» с ТЭЦ-5 (к юго-востоку от НБС); б) миграция на территории сада воздушных масс, загрязненных выбросами автотранспорта, движущегося по Надднепрянскому шоссе (одна из главных автотранспортных магистралей Киева; примыкает к территории сада с востока); в) распределение по территории локальных источников выбросов, связанных с хозяйственной деятельностью в НБС НАНУ; г) особенности рельефа территории; д) состояние, густота и высота древесно-кустарникового покрова. С учетом изложен- 
ного, пробы трансплантатов были экспонированы в пунктах, расположенных на следующих делянках и участках: 1 - «Берёзы»; 2 - «Горный сад» (на верхушке искусственного кургана); 3 - «Алтай и Западная Сибирь»; 4 - «Яблочный сад»; 5 - около забора, метров за 150 от крайней южной точки периметра НБС; 6 - «Плодовые»; 7 - между «Пакленовой дубравой» и насаждениями боярышника; 8 - «Степи Украины» (на верхушке искусственного кургана); 9 - «Кленовые»; 10 - верхняя часть Днепровского склона за делянкою «Сосны»; 11 - подножье Днепровского склона, около забора, крайняя северо-восточная точка периметра НБС; 12 - «Хоздвор» (рис. 1).

После завершения срока экспонирования штапики с образцами лишайника снимались и передавались в лабораторию для химического анализа.

Сбор и анализ аборигенных гипогимний, встречающихся на территории НБС, не делался: таких лишайников было слишком мало; произрастали они в большинстве случае не в тех точках, которые были намечены для исследования на предмет атмосферного загрязнения; да и травмировать не очень большую популяцию лишайника в ботаническом саду не представлялось целесообразным.
Обработка и химический анализ образцов трансплантатов лишайника H. physodes. Талломы экспонированных лишайников соскабливались с веточек, их нижняя часть тщательно механически очищалась от частиц коры и твердых частиц крупной пыли, песка, если таковые встречались. Образцы талломов не промывались. Каждая аналитическая проба составлялась из 9-13 розеток, в зависимости от их исходного высаженного количества растительного материала. Высушенные до воздушно-сухого веса розетки лишайников подвергались озолению мокрым способом в азотной кислоте с использованием микроволновой печи MWS-2 (Berghof, Германия). Измерения концентраций химических элементов в экстракте осуществлялись на плазменно-эмиссионном спектрометре ICAP 6300 DUO (Thermo-Fisher Corporation, США). Определялись $\mathrm{Ca}, \mathrm{K}, \mathrm{P}, \mathrm{S}, \mathrm{Mg}, \mathrm{Al}, \mathrm{Fe}, \mathrm{Mn}, \mathrm{Na}$, $\mathrm{Zn}, \mathrm{Sr}, \mathrm{Ba}, \mathrm{Ti}, \mathrm{Cu}, \mathrm{Pb}, \mathrm{Cr}, \mathrm{Ni}, \mathrm{V}, \mathrm{Cd}, \mathrm{Co}, \mathrm{Sb}$. Измерения проводились в 2-4 повторах, в зависимости от объема первичной навески анализируемого биоматериала. Содержание химических элементов пересчитывалось в микрограммы на грамм воздушно-сухого веса лишайникового таллома («мкг/г»). $K_{\kappa}$ или $K_{p}$ рассчитывались как частное от деления содержания

E

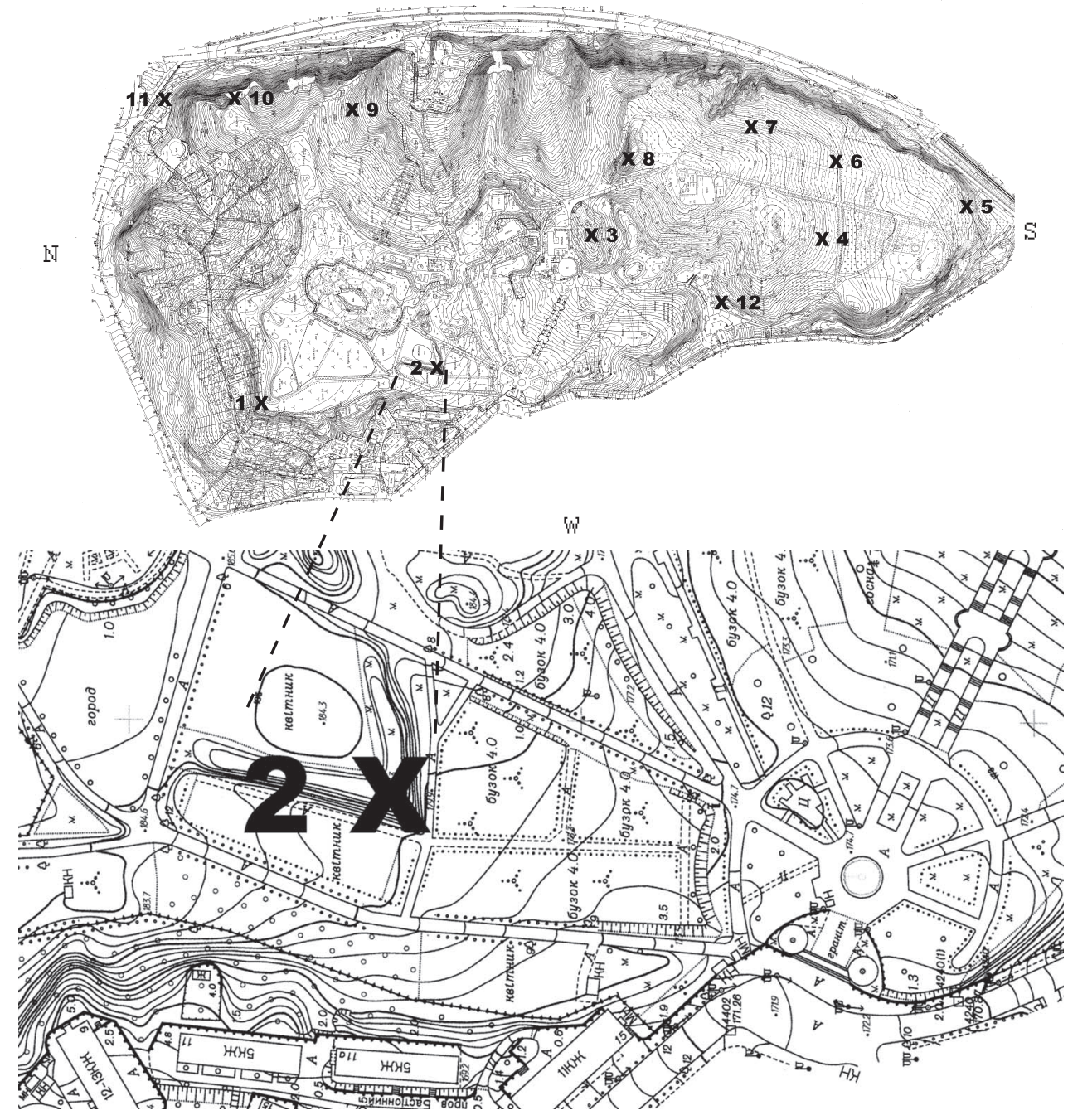

Pис. 1. Схема пунктов экспонирования трансплантатов лишайника Н. physodes на территории Национального ботанического сада им. Н.Н. Гришко НАН Украины в 2013-2014 гг. 
химического элемента в экспонированном образце на таковое в исходном (фоновом) лишайниковом материале, отобранном в вышеуказанных пунктах. Далее по тексту статьи, за исключением таблицы, абсолютные величины концентраций химических элементов в слоевищах даны без подписи «мкг/г» цифрами, набранными прямым шрифтом, а безразмерные величины $K_{\kappa}$ и $K_{p}$ даны цифрами, набранными курсивом.

\section{Результаты и их обсуждение}

Общие закономерности изменения содержания химических элементов в трансплантатах $H$. physodes

Среднее содержание химических элементов в исходных (фоновых) образцах лишайника, которые использовались для экспонирования, было следующим: $\mathrm{Ca}(9767)>\mathrm{K}(3000)>\mathrm{P}(1420)>\mathrm{S}(960)>\mathrm{Mg}$ $(886)>\mathrm{Al}(673)>\mathrm{Fe}(632)>\mathrm{Mn}(521)>\mathrm{Na}(81)>\mathrm{Zn}$ (59) $>\mathrm{Sr}(39)>\mathrm{Ba}(24)>\mathrm{Ti}(7,7)>\mathrm{Cu}(4,7)>\mathrm{Pb}(2,0)>$ $\mathrm{Cr}(1,7)>\mathrm{Ni}(1,3)>\mathrm{V}(0,72)>\mathrm{Cd}(0,55)>\mathrm{Co}(0,44)>$ $\mathrm{Sb}(0,027)$. Содержание химических элементов в любом живом организме является важным биогеохимическим показателем. Существует понятие видоспецифичности накопления растениями тех или иных химических элементов. Приведенный ряд абсолютного накопления является важной видовой биогеохимической характеристикой лишайника $H$. physodes, произрастающего в южной части Киевского Полесья. После экспонирования слоевищ гипогимнии в пределах города Киева естественный порядок величин накопления в них химических элементов нарушается. Уже только этот факт свидетельствует об изменении атмогеохимической обстановки и биогеохимических процессов в условиях мегаполиса. Усредненные по всем пунктам наблюдения величины содержания химических элементов в розетках полугодичных экспозиций следующие (жирным курсивом выделены химические элементы, которые сменили свое положение в ряду накопления по сравнению с фоном из-за более сильного накопления или вымывания из талломов экспонированных образцов):

- 0,5m: Ca $(9692)>\mathrm{K}(3778)>\boldsymbol{S}(2440)>\mathrm{P}(1793)>$ $\boldsymbol{F e}(1134)>\mathrm{Mg}(1070)>\mathrm{Al}(977)>\mathrm{Mn}(590)>\mathrm{Na}(138)$ $>\mathrm{Zn}(74)>\mathrm{Sr}(39)>\mathrm{Ba}(16,5)>\boldsymbol{C u}(12,0)>\mathrm{Ti}(7,59)>$ $\mathrm{Pb}(7,43)>\boldsymbol{N i}(4,0)>\mathrm{Cr}(1,7)>\boldsymbol{C d}(0,92)>\mathrm{V}(0,69)>\mathrm{Co}$ $(0,61)>\mathrm{Sb}(0,07)$

- 0,5x: Ca (12369) > S (2278) > Fe (1598) > Al (1201) $>\boldsymbol{M g}(1161)>\mathrm{P}(1142)>\boldsymbol{K}(1130)>\mathrm{Mn}(479)>\mathrm{Na}(221)$ $>\mathrm{Zn}(105)>\mathrm{Sr}(35)>\mathrm{Ba}(20,8)>\mathrm{Ti}(7,59)>\boldsymbol{P b}(7,02)>$ Ni $(3,0)>\boldsymbol{V}(2,66)>\mathrm{Cu}(2,55)>\mathrm{Cr}(1,98)>\mathrm{Co}(1,21)>$ $\mathrm{Cd}(0,72)>\mathrm{Sb}(0,027)$.

Однако абсолютное содержание химических элементов в слоевищах трансплантатов не дает полной картины об интенсивности накопления или, наоборот, десорбции химических элементов из растений во время экспозиции. Более информативными будут величины $K_{\kappa}$ и $K_{p}$ (табл. 1$)$.

Пользуясь данными таблицы, составим ряды накопления $\left(K_{K}\right)$ и рассеяния $\left(K_{p}\right)$ химических элементов за теплое и холодное полугодия по всем пунктам экспонирования. Обобщенные за каждый полугодичный период экспонирования ряды $K_{\kappa}$ и $K_{p}$ для изученных химических элементов будут такими (вертикальными чертами значения коэффициента, равные единице, а также очень близкие к ней значения $1,05-0,94$, отделены от значений $K_{\kappa}$ слева и от значений $K_{p}$ справа, и кроме того отмечены подчеркиванием): 0,5m: $\mathrm{Pb}(3,87)>\mathrm{Ni}(3,08)>\mathrm{Sb}(2,59) \approx \mathrm{S}(2,57) \approx \mathrm{Cu}$ $(2,54)>\mathrm{Fe}(1,76) \approx \mathrm{Na}(1,75)>\mathrm{Cd}(1,70)>\mathrm{Al}(1,47)=$ $\operatorname{Mg}(1,47)>\operatorname{Co}(1,33)>\mathrm{K}(1,28)=\mathrm{P}(1,28)=\mathrm{Zn}(1,28)>$ $\operatorname{Mn}(1,11)>\| \underline{\operatorname{Sr}(1,05) \approx \mathrm{Cr}(1,01) \approx \mathrm{Ti}(0,99) \approx \mathrm{Ca}(0,98)}$ $\approx \mathrm{V}(0,96) \|>\mathrm{Ba}(0,69)$;

0,5x: $\mathrm{V}(3,69)>\mathrm{Pb}(3,44)>\mathrm{Co}(2,95)>\mathrm{Na}(2,66)>\mathrm{Fe}$ $(2,58)>\mathrm{S}(2,34) \approx \mathrm{Ni}(2,31)>\mathrm{Al}(1,77) \approx \mathrm{Zn}(1,75)>\mathrm{Mg}$ $(1,36)>\mathrm{Ca}(1,29)=\mathrm{Cd}(1,29)>\mathrm{Cr}(1,15)>\| \underline{\mathrm{Sb}(1,00) \approx}$ $\underline{\operatorname{Ti}(0,96) \approx \operatorname{Mn}(0,94)} \|>\mathrm{Ba}(0,89) \approx \operatorname{Sr}(0,86)>\mathrm{P}(0,79)$ $>\mathrm{Cu}(0,55)>\mathrm{K}(0,37)$.

Мы считаем, что в интервале $1,05-0,94$ отклонения $K$ от 1 обусловлены скорее погрешностями измерения, чем реальными геохимическими процессами, то есть за период экспонирования слоевищ изменения в содержании данного химического элемента отсутствовали. В летнюю полугодичную экспозицию к таким элементам относятся $\mathrm{Sr}, \mathrm{Cr}, \mathrm{Ti}, \mathrm{Ca}, \mathrm{V}$; в зимнюю - Sb, Ti, Mn.

Чем больше значение $K_{\kappa}$ в ряду накопления имеет химический элемент, тем сильнее его поглощение лишайником из воздушной среды, следовательно, тем выше его содержание в ней. Если в лишайникетрансплантате $K_{\kappa}$ или $K_{p}$ для тех или иных химических элементов колеблются около единицы, то это означает, что либо содержание этих элементов в воздухе не увеличивается, либо организм растения даже при повышенных концентрациях химического элемента в воздухе отказывается поглощать его сильнее. Разделить эти две причины при интерпретации $K_{\kappa}$ и $K_{p}$ сложно.

Как подчеркивалось, снижение содержания того или иного химического элемента в лишайнике-трансплантате в большинстве случаев (исключение может составлять, например, титан) свидетельствует не о том, что в условиях техногенной нагрузки, в которых проводится эксперимент по трансплантации, в воздухе уменьшается концентрация соответствующего химического элемента, а о том, что в новых геохимических условиях поглощение веществ из окружающей среды становится менее интенсивным по физиологическим или геохимическим причинам. Заметим, что в нашем эксперименте $K_{\kappa}$ и $K_{p}$ для периодов летней и зимней экспозиции отличаются. Это является косвенным подтверждением того, что в период экспозиции на установление уровней содержания в организме лишайника того или иного химического элемента оказывает влияние и фактор физиологической активности организма, и причина, связанная с закислением атмосферных осадков в мегаполисе.

Важным показателем пространственной структуры поля атмосферного загрязнения территории является разброс (дисперсия) значений содержания техногенных продуктов в объектах мониторинга. Высокие величины дисперсии указывают на наличие на территории источников выбросов, их неравномерное по ней размещение, а также на сложность ландшафтных условий воздушной миграции и седиментации поллютантов. Оценивая с этих позиций результаты нашего трансплантационного эксперимента, подчеркнем, что наибольший разброс по 12 пунктам экспозиции на территории НБС НАНУ имеют такие химические элементы, как $\mathrm{Cu}, \mathrm{Na}, \mathrm{Ni}$, $\mathrm{Sb}, \mathrm{V}, \mathrm{Zn}$, а наименьший - K, P, Тi. Соответственно мощность источников выбросов и неравномерность их распределения по территории, а также сложность атмосферной миграции и седиментации для первой 
Коэффициенты концентрирования $(>1)$ и рассеивания $(<1)$ химических элементов в талломах лишайника Hypogymnia physodes (L.) Nyl., трансплантированных в 12 пунктах на территории Национального ботанического сада НАН Украины на полгода в теплый $(0,5 m)$ и холодный $(0,5 x)$ сезон, на 1 год $(1,0)$ и на полтора года $(1,5)$

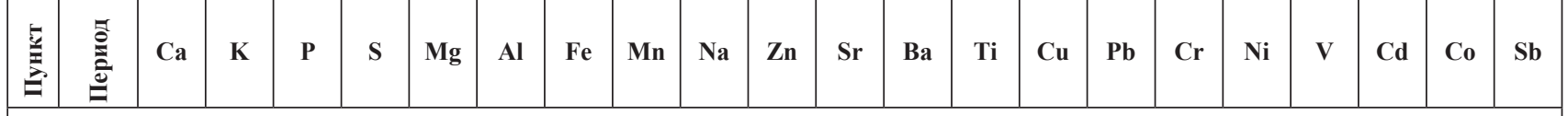

\begin{tabular}{|c|c|c|c|c|c|c|c|c|c|c|c|c|c|c|c|c|c|c|c|c|c|c|}
\hline \multirow{2}{*}{1} & $0,5 m$ & 0,8 & 1,0 & 1,1 & 2,0 & 0,8 & 1,1 & 1,4 & 0,9 & 0,7 & 1,4 & 1,1 & 0,5 & 1,0 & 1,6 & 1,8 & 1,0 & 3,4 & 1,0 & 1,5 & 1,0 & 1,3 \\
\hline & $0,5 x$ & 1,1 & 0,2 & 0,7 & 2,2 & 1,1 & 1,6 & 2,4 & 1,0 & 2,4 & 1,5 & 0,9 & 0,6 & 0,7 & 0,1 & 2,9 & 0,9 & 2,6 & 3,3 & 1,3 & 2,1 & 1,0 \\
\hline \multirow{4}{*}{2} & $0,5 m$ & 0,8 & 1,0 & 1,3 & 2,1 & 1,1 & 1,3 & 1,7 & 0,9 & 0,9 & 1,3 & 1,1 & 0,3 & 0,9 & 2,1 & 3,1 & 1,1 & 4,2 & 1,1 & 1,1 & 1,2 & 1,5 \\
\hline & $0,5 x$ & 1,0 & 0,3 & 0,7 & 2,1 & 1,4 & 1,6 & 1,9 & 0,9 & 2,1 & 1,7 & 0,5 & 0,4 & 0,9 & 0,1 & 2,8 & 0,6 & 1,5 & 2,5 & 1,2 & 2,2 & 1,0 \\
\hline & 1,0 & 1,8 & 0,8 & 0,8 & 2,6 & 1,4 & 2,1 & 2,5 & 1,2 & 2,1 & 1,9 & 1,0 & 1,0 & 1,0 & 1,8 & 3,7 & 2,1 & 2,5 & 5,5 & 1,3 & 2,7 & 1,1 \\
\hline & 1,5 & 1,6 & 1,0 & 1,1 & 3,3 & 1,6 & 2,4 & 2,8 & 1,1 & 2,8 & 2,3 & 1,1 & 1,5 & 1,0 & 1,3 & 5,2 & 2,0 & 2,9 & 5,3 & 2,0 & 3,4 & \\
\hline \multirow{3}{*}{3} & $0,5 m$ & 1,3 & 1,6 & 1,3 & 2,2 & 1,8 & 1,2 & 1,6 & 0,9 & 1,3 & 1,3 & 1,0 & 0,4 & 1,0 & 2,0 & 2,7 & 1,0 & 4,1 & 1,0 & 1,4 & 1,1 & 1,5 \\
\hline & $0,5 x$ & 0,9 & 0,3 & 0,8 & 2,8 & 1,4 & 1,8 & 2,5 & 0,9 & 3,0 & 1,7 & 0,6 & 0,5 & 1,1 & 0,1 & 3,4 & 0,9 & 1,5 & 2,8 & 1,4 & 2,3 & 1,0 \\
\hline & 1,0 & 2,0 & 1,2 & 1,0 & 2,7 & 2,5 & 2,1 & 2,5 & 1,2 & 3,4 & 2,0 & 1,5 & 1,2 & 1,0 & 0,5 & 4,1 & 1,8 & 2,6 & 6,6 & 1,4 & 2,9 & 0,4 \\
\hline \multirow{4}{*}{4} & $0,5 m$ & 0,8 & 0,9 & 1,3 & 3,1 & 1,0 & 1,3 & 1,5 & 1,0 & 1,7 & 0,9 & 1,1 & 0,6 & 1,1 & 2,4 & 4,1 & 1,0 & 1,1 & 1,0 & 1,6 & 1,4 & 3,2 \\
\hline & $0,5 x$ & 1,1 & 0,7 & 1,0 & 2,7 & 1,2 & 1,8 & 1,9 & 0,9 & 2,4 & 1,7 & 0,8 & 1,0 & 0,9 & 0,1 & 3,8 & 1,5 & 2,5 & 4,3 & 1,5 & 3,3 & 1,0 \\
\hline & 1,0 & 1,2 & 0,9 & 1,0 & 2,6 & 1,4 & 2,5 & 3,7 & 1,1 & 3,7 & 1,8 & 0,9 & 1,5 & 1,2 & 0,4 & 4,4 & 2,2 & 2,6 & 5,9 & 1,4 & 3,2 & 1,5 \\
\hline & 1,5 & 1,8 & 1,1 & 1,2 & 3,2 & 1,7 & 2,4 & 3,2 & 0,9 & 2,5 & 2,4 & 1,3 & 2,4 & 1,0 & 1,5 & 4,0 & 1,8 & 3,2 & 4,9 & 2,5 & 3,6 & \\
\hline \multirow{3}{*}{5} & $0,5 m$ & 1,0 & 1,7 & 1,1 & 3,1 & 1,5 & 1,8 & 2,7 & 1,2 & 3,3 & 1,3 & 1,0 & 1,0 & 1,0 & 3,7 & 6,2 & 1,1 & 1,7 & 1,0 & 2,1 & 1,6 & 4,9 \\
\hline & $0,5 x$ & 1,3 & 0,8 & 0,9 & 2,3 & 1,5 & 1,6 & 2,0 & 0,9 & 2,5 & 1,8 & 0,9 & 0,8 & 0,8 & 0,1 & 3,5 & 1,6 & 2,3 & 4,5 & 1,3 & 2,9 & 1,0 \\
\hline & 1,0 & 2,4 & 1,0 & 0,9 & 2,3 & 2,0 & 3,0 & 6,0 & 1,1 & 5,0 & 2,8 & 2,0 & 3,1 & 1,8 & 5,2 & 4,7 & 3,8 & 5,6 & 8,4 & 1,2 & 3,5 & 3,0 \\
\hline \multirow{4}{*}{6} & $0,5 m$ & 0,9 & 1,5 & 1,2 & 2,7 & 1,3 & 1,2 & 1,6 & 1,1 & 1,6 & 0,8 & 1,1 & 0,5 & 1,0 & 2,6 & 3,3 & 1,0 & 2,0 & 1,0 & 1,9 & 1,2 & 3,4 \\
\hline & $0,5 x$ & 2,1 & 1,2 & 1,0 & 2,2 & 2,4 & 1,9 & 2,4 & 0,9 & 1,7 & 1,8 & 1,5 & 1,1 & 1,0 & 0,2 & 3,9 & 1,8 & 2,6 & 6,7 & 1,1 & 3,5 & 1,0 \\
\hline & 1,0 & 1,6 & 0,8 & 1,0 & 2,7 & 1,4 & 1,8 & 2,5 & 1,0 & 4,2 & 2,1 & 1,3 & 1,1 & 1,0 & 2,9 & 4,4 & 2,2 & 2,7 & 5,0 & 1,4 & 3,4 & 1,9 \\
\hline & 1,5 & 1,9 & 1,3 & 1,2 & 3,8 & 1,4 & 2,3 & 3,3 & 1,0 & 4,0 & 3,2 & 2,1 & 1,9 & 1,1 & 1,5 & 5,0 & 2,0 & 2,9 & 6,7 & 2,8 & 3,6 & 1,9 \\
\hline \multirow{4}{*}{7} & $0,5 m$ & 0,6 & 1,4 & 1,4 & 3,3 & 1,1 & 1,7 & 1,6 & 1,6 & 4,9 & 1,0 & 0,9 & 0,6 & 1,0 & 3,0 & 3,8 & 1,0 & 1,4 & 1,0 & 1,9 & 1,6 & 3,6 \\
\hline & $0,5 x$ & 1,1 & 0,1 & 0,8 & 2,6 & 1,2 & 1,9 & 2,6 & 0,9 & 2,4 & 1,8 & 0,7 & 0,8 & 0,8 & 0,1 & 3,7 & 1,1 & 2,2 & 3,4 & 1,4 & 3,3 & 1,0 \\
\hline & 1,0 & 1,4 & 1,0 & 1,0 & 2,3 & 1,8 & 2,3 & 3,1 & 1,1 & 3,0 & 2,1 & 1,1 & 1,7 & 1,3 & 0,3 & 4,2 & 2,3 & 3,4 & 6,4 & 1,2 & 3,1 & 2,6 \\
\hline & 1,5 & 1,5 & 1,1 & 1,2 & 3,0 & 1,2 & 2,0 & 2,6 & 1,2 & 3,8 & 2,4 & 1,4 & 2,1 & 1,1 & 1,4 & 3,6 & 1,9 & 2,6 & 5,0 & 2,7 & 3,0 & \\
\hline \multirow{3}{*}{8} & $0,5 m$ & 1,8 & 1,1 & 1,8 & 2,3 & 1,2 & 1,8 & 2,1 & 1,7 & 1,4 & 2,2 & 1,1 & 1,8 & 1,1 & 1,9 & 3,7 & 1,0 & 6,5 & 0,7 & 1,9 & 1,7 & 2,2 \\
\hline & $0,5 x$ & 1,5 & 0,1 & 0,7 & 2,4 & 1,1 & 1,4 & 1,9 & 0,9 & 2,3 & 1,7 & 0,9 & 0,4 & 1,2 & 0,1 & 3,0 & 0,7 & 1,6 & 2,5 & 1,3 & 2,5 & 1,0 \\
\hline & 1,0 & 1,4 & 0,6 & 0,8 & 3,0 & 1,3 & 2,2 & 2,5 & 1,2 & 3,5 & 2,1 & 0,8 & 1,1 & 1,0 & 0,2 & 3,7 & 1,9 & 2,3 & 5,3 & 1,3 & 2,6 & 0,4 \\
\hline \multirow{4}{*}{9} & $0,5 m$ & 0,7 & 1,5 & 1,2 & 2,8 & 1,4 & 1,3 & 1,4 & 1,2 & 1,7 & 1,0 & 0,9 & 0,5 & 1,0 & 2,4 & 4,4 & 1,0 & 2,5 & 1,0 & 1,4 & 1,3 & 3,0 \\
\hline & $0,5 x$ & 1,0 & 0,2 & 0,8 & 2,3 & 1,1 & 1,5 & 2,3 & 0,9 & 2,2 & 1,4 & 0,9 & 0,4 & 0,9 & 0,4 & 2,9 & 0,7 & 1,8 & 2,7 & 1,3 & 2,3 & 1,0 \\
\hline & 1,0 & 1,5 & 1,4 & 1,1 & 2,7 & 1,6 & 1,8 & 2,2 & 1,0 & 2,4 & 1,8 & 1,1 & 0,7 & 0,9 & 0,2 & 3,8 & 1,9 & 2,7 & 5,3 & 1,5 & 2,6 & 0,7 \\
\hline & 1,5 & 1,6 & 1,7 & 1,4 & 3,5 & 1,9 & 2,0 & 2,5 & 1,1 & 4,6 & 2,5 & 1,3 & 1,5 & 0,9 & 4,4 & 4,8 & 2,1 & 3,3 & 5,1 & 2,4 & 3,4 & \\
\hline \multirow{3}{*}{10} & $0,5 m$ & 0,9 & 1,4 & 1,2 & 2,8 & 1,3 & 1,3 & 1,3 & 1,4 & 1,1 & 1,0 & 1,1 & 0,7 & 1,0 & 2,7 & 4,5 & 1,1 & 2,4 & 1,0 & 2,0 & 1,4 & 3,0 \\
\hline & $0,5 x$ & 1,7 & 0,2 & 0,7 & 2,2 & 1,5 & 2,5 & 5,7 & 0,9 & 6,1 & 2,4 & 1,3 & 2,2 & 1,4 & 3,9 & 3,9 & 1,8 & 4,3 & 5,4 & 1,1 & 3,9 & 1,0 \\
\hline & 1,0 & 1,6 & 1,1 & 1,0 & 2,8 & 1,6 & 1,9 & 1,9 & 1,0 & 2,9 & 2,4 & 1,0 & 1,4 & 0,9 & 0,2 & 4,7 & 2,0 & 1,8 & 4,5 & 1,6 & 3,5 & 1,9 \\
\hline \multirow{3}{*}{11} & $0,5 m$ & 1,3 & 1,1 & 1,3 & 2,1 & 0,9 & 2,1 & 2,5 & 0,6 & 0,8 & 1,9 & 1,0 & 0,7 & 1,0 & 3,7 & 4,9 & 1,0 & 4,8 & 1,1 & 2,0 & 1,1 & 1,6 \\
\hline & $0,5 x$ & 1,3 & 0,1 & 0,8 & 2,2 & 1,0 & 1,9 & 3,2 & 1,1 & 2,3 & 1,7 & 0,7 & 1,3 & 0,9 & 1,0 & 4,0 & 1,1 & 2,9 & 3,5 & 1,2 & 3,6 & 1,0 \\
\hline & 1,0 & 1,4 & 1,4 & 0,8 & 1,1 & 2,9 & 1,5 & 3,0 & 3,4 & 1,2 & 5,6 & 2,6 & 1,0 & 1,1 & 1,4 & 4,3 & 4,7 & 2,6 & 2,5 & 6,2 & 1,6 & 3,2 \\
\hline 12 & $0,5 x$ & 1,5 & 0,2 & 0,7 & 2,2 & 1,1 & 1,7 & 2,4 & 1,0 & 2,6 & 1,8 & 0,7 & 1,2 & 1,0 & 0,1 & 3,4 & 1,1 & 2,3 & 2,7 & 1,2 & 3,0 & 1,0 \\
\hline & & & & & & & & & & & & & & & & & & & & & & \\
\hline 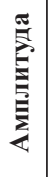 & 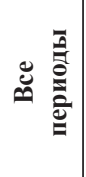 & $\begin{array}{l}+ \\
i \\
1 \\
0 \\
0\end{array}$ & $\stackrel{5}{5}$ & $\frac{\infty}{i}$ & $\begin{array}{l}\infty \\
\stackrel{n}{\prime} \\
=\end{array}$ & $\begin{array}{c}\hat{a} \\
\text { i } \\
1 \\
\infty \\
0\end{array}$ & $\begin{array}{l}0 \\
\stackrel{1}{\Rightarrow} \\
\Rightarrow\end{array}$ & $\begin{array}{l}0 \\
0 \\
1 \\
?\end{array}$ & $\begin{array}{l}\nabla_{0} \\
i \\
1 \\
0 \\
0\end{array}$ & $\begin{array}{l}\overrightarrow{6} \\
1 \\
\hat{0}\end{array}$ & $\begin{array}{l}0 \\
i \\
1 \\
0 \\
0\end{array}$ & $\begin{array}{l}0 \\
i \\
1 \\
n \\
0\end{array}$ & $\begin{array}{l}\vec{m} \\
1 \\
m\end{array}$ & $\begin{array}{l}\vec{i} \\
\overrightarrow{0}\end{array}$ & $\begin{array}{l}2 \\
n \\
\frac{1}{0}\end{array}$ & $\begin{array}{l}\text { N } \\
1 \\
\infty \\
-1\end{array}$ & $\begin{array}{l}\tilde{f} \\
i \\
b \\
0\end{array}$ & $\begin{array}{l}n \\
6 \\
1 \\
= \\
-1\end{array}$ & $\begin{array}{c}+ \\
\infty \\
1 \\
0\end{array}$ & $\begin{array}{l}2 \\
6 \\
1 \\
=\end{array}$ & $\begin{array}{c}9 \\
1 \\
0\end{array}$ & $\begin{array}{l}\sigma_{+} \\
\dot{1} \\
\dot{0}\end{array}$ \\
\hline
\end{tabular}


группы химических элементов наиболее высокая, для второй - самая низкая.

Из общих закономерностей изменения содержания химических элементов в талломах экспонированных гипогимний важным является также то, что в них или накапливается $\left(K_{k}\right)$, или рассеивается $\left(K_{p}\right)$ большинство химических элементов. Наиболее интенсивно и устойчиво в слоевищах трансплантированных лишайников накапливаются $\mathrm{Al}, \mathrm{Cd}, \mathrm{Fe}, \mathrm{Ni}, \mathrm{Pb}, \mathrm{S}, \mathrm{V}$; для них вообще не отмечены $K_{p}$. Это свидетельствует не только о сильной атмосферной нагрузке на экосистемы загрязнителей, содержащих эти элементы (для алюминия в условиях Киева они, например, вообще не свойственны), но и о важной роли биохимических и биогеохимических механизмов накопления перечисленных химических элементов слоевищами H. physodes. Наиболее часто и сильно уменьшаются в слоевищах лишайников во время экспонирования такие химические элементы, как К, Ва и Сu. Ухудшения поглощения биогенного калия в техногенных условиях - факт известный [5]. Поведение бария мало исследовано, а меди - типичного тяжелого металлазагрязнителя атмосферы в городских агломерациях и одновременно важного биогенного микроэлемента - оно феноменально. В одних пунктах трансплантации она очень сильно накапливается в слоевищах, а в других - не менее интенсивно вымывается из них. Первое характерно для летнего периода экспонирования, второе - больше для зимнего. Похожее явление наблюдали и другие исследователи [4, 7] и объясняли его сезонными отличиями в поступлении аэрозолей, содержащих медь, на поверхность экспонируемых слоевищ. Мы полагаем, что резкое уменьшение содержания меди зимой в трансплантатах H. physodes обусловливается также и влиянием на ее слоевища кислых осадков, способных усиливать мобилизацию ионов $\mathrm{Cu}$ и стимулировать их вымывание из таллома. Большее же закисление атмосферных осадков в зимний период объясняется тем, что в отопительный сезон имеют место наибольшие объемы атмосферных выбросов ТЭЦ-5 - одного из главных техногенных объектов, формирующих поле загрязнения приземного воздуха на изученной территории.

Локальные особенности изменения содержания химических элементов в трансплантатах H. physodes на территории НБС НАНУ

Накопление и рассеивание химических элементов в слоевищах экспонированных лишайников очень неравномерное в разных пунктах высадки. Это говорит о непростом характере атмотехногенного поля загрязнения на изученной территории. Возможны также вариации эколого-физиологических условий произрастания (жизнедеятельности) высаженных лишайников, что тоже может сказываться на интенсивности накопления ими химических элементов из атмосферы. Однако эта причина имеет, по нашему мнению, в целом подчиненное значение.

1 - «Берёзы». Этот пункт наблюдения находится в закрытом месте в дальнем северо-западном углу НБС, вне зоны прямого влияния источников загрязнения атмосферы. Он, согласно результатам нашего эксперимента, - один из наименее загрязненных. Летом в экспонированных образцах здесь наименьшие $K_{\kappa}$ у $\mathrm{S}, \mathrm{Al}, \mathrm{Cu}, \mathrm{Pb}, \mathrm{Sb}$ и наименьшие $K_{p}$ у $\mathrm{Mg}, \mathrm{Na}, \mathrm{Cr}$, Со. Зимой - наименьший $K_{\kappa}$ у Тi.
2 - «Горный сад». Пункт также расположен далеко от источников выбросов, но, в отличие от предыдущего, не в тихом месте, а на верхушке искусственного кургана, открытой ветрам всех румбов. Сюда свободно могут приходить гомогенизированные воздушные массы, которые содержат аэрозоли и газы, поступившие в атмосферу из высоких источников выбросов мегаполиса. В теплый период $K_{\kappa}$ у $\mathrm{Mg}, \mathrm{Mn}, \mathrm{Na}, \mathrm{Sr}, \mathrm{Ti}$, $\mathrm{Cr}, \mathrm{V}, \mathrm{Cd}$ мало отличаются от единицы, то есть изменений содержания этих химических элементов в слоевищах не существенно. Однако $\mathrm{S}(2,1)$ и $\mathrm{Ni}(4,15)$ в них накапливаются заметно. Мы связываем это с влиянием воздушных потоков из верхних слоев приземной атмосферы, несущих компоненты высоких выбросов всего мегаполиса, на пункт экспонирования (напомним, он расположен на вершине кургана). Такое предположение выглядит еще более правдоподобным, если учесть следующее. Другие пункты проведения эксперимента, расположенные на высоких открытых всем ветрам местах, тоже характеризуются большими летними $K_{\kappa}$ никеля; это пункт 8 тоже вершина искусственного кургана на восточном участке территории сада $(6,5)$ и пункт 3 - высокое плато в центральной его части $(4,1)$. В пунктах высадки трансплантатов на возвышенных формах рельефа, где воздушные массы отличаются повышенной турбулентностью, наблюдаем одну и ту же картину: высокие $K_{\kappa}$ никеля в слоевищах гипогимнии летней полугодичной экспозиции. Такая тенденция в накоплении металла экспонированными лишайниками свидетельствует, по нашему мнению, о том, что Ni выступает индикатором влияния воздушных масс, гомогенно загрязненных смесью высоких выбросов города в целом, на возвышенные участки изученной территории. Специфических локальных источников никелевого загрязнения атмосферы в Киеве нет. Возможно, этот представитель тяжелых металлов в данном случае является показателем влияния именно общегородской, если можно так выразиться, загрязненной воздушной массы.

В холодный период в трансплантатах пункта «Горный сад» заметно концентрируются S, Pb, V, Co, но это характерно и для других точек трансплантационного эксперимента. $K_{\kappa}$ для $\mathrm{S}(2,6), \mathrm{Pb}(3,7), \mathrm{V}(5,5)$, Со $(2,7)$ в слоевищах годичной экспозиции свидетельствует о загрязнении воздуха этими элементами в данном пункте на протяжении всего года. Но их величины не являются экстремальными. Уровни атмосферного загрязнения пункта высадки трансплантатов «Горный сад» серой, свинцом, кобальтом при годичной экспозиции могут расцениваться как своеобразный местный «геотехнический фон» для территории НБС НАНУ.

3 - «Алтай и Западная Сибирь». По $K_{\kappa}$ за теплый период пункт мало чем выделяется, кроме высокого $K$ никеля, о чем говорилось выше. Зимой заметно усиливается накопление $\mathrm{Fe}(2,5), \mathrm{Na}(3,0)$ и $\mathrm{V}(2,8)$. За год экспозиции этот пункт выглядит достаточно грязным. Особо обращают на себя внимание высокие значения $K_{\kappa} \mathrm{Ca}(2,0)$ и $\mathrm{Mg}(2,5)$, что можно интерпретировать как показатель достаточно высокой нагрузки терригенной пыли на этот пункт.

4 - «Яблочный сад». Пункт размещен на склоне южной экспозиции, принимающем на себя «удар» шлейфа выбросов ТЭЦ-5 при южных и юго-восточных ветрах. За время летней экспозиции тут зафик- 
сированы высокие значения $K_{\kappa}$ для $\mathrm{S}(3,1), \mathrm{Pb}(4,1)$ и $\mathrm{Sb}(3,2)$ в слоевищах трансплантатов. За время зимней - наибольший рост концентраций в слоевищах фиксируется у V $(4,3)$ и $\mathrm{Pb}(3,8)$, что свидетельствует о влиянии на этот пункт выбросов ТЭЦ-5, усиливающемся во время отопительного сезона.

5 - около ограды, за 150 м от крайней южной точки территории НБС. Этот пункт, по нашим наблюдениям, является наиболее загрязненным на всей изученной территории. Он расположен в нижней трети Днепровского склона, имеет юго-восточную экспозицию, является самым близким к промзоне «Выдубечи», а также находится в зоне влияния выбросов автомобильного транспорта, движущегося по Надднепрянскому шоссе. От последнего загрязненные автомобильными выхлопами воздушные массы могут при южных и юго-восточных ветрах беспрепятственно достигать этого пункта высадки трансплантатов; он не защищен ни неровностями рельефа, ни древесно-кустарниковой растительностью. В пункте наблюдаются высокие коэффициенты концентрации для проб летнего периода экспозиции и еще большие - для годичного периода трансплантации: в слоевищах существенно возрастает содержание $\mathrm{Ca}(2,4)$, $\mathrm{Al}(3,0), \mathrm{Fe}(6,0), \mathrm{Na}(5,0), \mathrm{Ba}(3,1), \mathrm{Cu}(5,2), \mathrm{Cr}(3,8), \mathrm{Ni}$ $(5,6), \mathrm{V}(8,4), \mathrm{Sb}(3,3)$. Набор химических элементов говорит о том, что имеет место комплексное влияние Надднепрянского шоссе и промзоны «Выдубечи» на приземную атмосферу: в ней накапливаются ассоциированные с крупно- и мелкодисперсными аэрозолями загрязнители атмосферы, обусловленные производственными выбросами, автомобильными выхлопами, истиранием металлических механизмов движущегося транспорта, а также терригенная пыль, поднятая с обочин дороги и с промплощадок. А вот накопления серы, содержащейся в газовой фазе, не наблюдается: слишком близко пункт расположен к главному источнику выбросов сернистых газов - к трубе ТЭЦ-5: шлейф ее выбросов не успевает здесь осесть и достичь земной поверхности.

Для пункта 5 важен также аэродинамический фактор формирования поля загрязнения приземной атмосферы. Зимой часто меняется направление господствующих ветров и затухают конвективные процессы, «ответственные» за перенос атмосферных поллютантов вверх по Днепровскому склону - от источников загрязнения до пункта трансплантации. Поэтому большие величины $K_{k}$ в слоевищах лишайников в холодный период экспозиции не наблюдаются (даже с учетом того, что зимой ТЭС-5 работает усиленно).

6 - «Плодовые». Особенности атмосферного загрязнения в этом пункте трансплантации во многом противоположны таковым для пункта 5. Летом на участке не наблюдаются высокие значения $K_{\kappa}$ для экспонировавшихся образцов $H$. physodes. Напротив, зимой $K_{\kappa}$ заметно возрастают для щелочных и щелочноземельных элементов $\mathrm{Ca}(2,1), \mathrm{Mg}(2,4), \mathrm{Sr}$ $(1,5)$; а также для $\mathrm{Pb}(3,9), \mathrm{Cr}(1,8), \mathrm{V}(6,7), \mathrm{Co}(3,5)-$ представителей группы тяжелых металлов. Перечисленные химические элементы характерны для крупно- и мелкодисперсных выбросов трубы ТЭЦ; по-видимому, зимой в пункте 6 происходит их интенсивное оседание из дымового шлейфа. Однако, как и в пункте 5 , в пункте 6 наблюдения в зимний период экспонирования в слоевищах не растет бо- лее чем в среднестатистических пределах количество серы - компонента газовой фракции выбросов ТЭЦ. Значит, газы мигрируют в атмосфере дальше, чем аэрозоли, и «проходят» пункт 6, не влияя на нее существенно сильнее.

Сравнивая особенности накопления химических элементов в трансплантатах в соседних пунктах 5 и 6, можно прийти к заключению, что на распределение поллютантов факела ТЭЦ-5 сильное влияние оказывает гипсометрический фактор. Пункт 5 расположен на несколько метров ниже по отношению к оголовку дымовой трубы ТЭЦ, нежели пункт 6. Но этого оказывается достаточно для того, чтобы факел выбросов электростанции не успевал оседать в полном объеме в более близком к ней пункте 5, а «обрушивал» основную массу содержащихся в нем поллютантов на пункт 6, который в плане находится дальше от электростанции, чем пункт 5.

Что касается другого мощного источника атмосферных выбросов - Надднепрянского шоссе, то на пути переноса загрязненных воздушных масс от него к пункту 5 отсутствует такой важный аэродинамический геохимический барьер, как плотные древеснокустарниковые насаждения. А пункт 6 такой барьер имеет.

Таким образом, между пунктами трансплантации 5 и 6 , расположенными в зоне воздействия дымового факела высоких выбросов ТЭЦ и (в меньшей мере) низких атмосферных выбросов автомобильного транспорта, движущегося по Надднепрянскому шоссе, имеются важные различия физико-географического характера, влияющие на седиментацию воздушных загрязнителей. Это обусловливает значительное, в первую очередь сезонное различие в поглощении продуктов техногенеза лишайниками в этих двух соседних пунктах.

7 - между «Пакленовой дубравой»и насаждениями боярышника. Пункт расположен в верхней части склона, окружен густой древесно-кустарниковой растительностью, что усложняет проникновение сюда загрязненных воздушных масс. Летом тут наблюдаются высокие значения $K_{\kappa}$ у $\mathrm{S}(3,3)$ и $\mathrm{Na}(4,9)$ и относительно высокие у $\mathrm{Cu}$ и $\mathrm{Pb}$, что указывает на влияние газовой и мелко-аэрозольной составляющей выбросов промзоны «Выдубечи», которая лучше проходит через растительный аэродинамический барьер, чем крупнодисперсные фракции. Зимой высокие значения $K_{\kappa}$ для трансплантатов из пункта 7 не характерны. В годичном тренде $K_{\kappa}$ у S и тяжелых металлов заметно повышаются, но экстремальных значений не достигают.

8 - «Степи Украины». Вместе с пунктом 2 («Горный сад») пункт 8 является наивысшим на территории НБС. Про общие черты воздушного загрязнения в обоих пунктах трансплантации сказано выше. Но между пунктами 2 и 8 есть и различия. Прежде всего, обращает на себя внимание, что в летний период здесь относительно интенсивно в слоевищах трансплантатов накапливаются все исследованные химические элементы, при этом $K_{\kappa}$ никеля именно в пункте 8 достигает наивысшего значения $(6,5)$ среди всех образцов всех периодов экспонирования в нашем эксперименте. Многие из химических элементов, умеренно накапливающихся в трансплантатах пункта 8 (Ca, Al, Fe, Mn, Ba, Ti), связаны с терригенной пылью. К пункту 8 как к самому высокому и расположенно- 
му близко к бровке Днепровского склона (что делает его хорошо продуваемой ветрами восточных румбов) терригенная пыль поступает практически беспрепятственно. Предыдущий же по высоте пункт 2 находится в глубине территории НБС - значительно дальше от бровки Днепровского склона (рис. 1) и поэтому хуже обдувается ветрами восточных румбов, несущих терригенную пыль с Левобережья и обладающих повышенной турбулентностью, что имеет важное значение для воздушного переноса крупнодисперсных частиц.

Следующие три пункта экспонирования имеют то общее, что расположены на северо-востоке территории НБС вдали от источников выбросов промзоны «Выдубечи», вдоль Днепровского склона, на средних и низких высотных уровнях. Общим фактором техногенного влияния на них являются автотранспортные выбросы Надднепрянского шоссе, а также воздушные массы, загрязненные промышленными предприятиями Левого берега (в частности, выбросами ТЭЦ-2 и ТЭЦ-6). Пункты 9 и 10 расположены на оползневых цирках Днепровского склона, а пункт $11-$ у его подножья. Для достижения двух первых пунктов трансплантации загрязненные воздушные массы от Надднепрянского шоссе должны подняться примерно до 2/3 высоты Днепровского склона (это обеспечивается восточными ветрами и конвективными движениями воздуха). Пункт же 11 доступен для загрязненных автотранспортными выбросами воздушных масс по горизонтали, он расположен практически на одном гипсометрическом уровне с дорогой. Важно также то, что пункты 9 и 11 в теплый период экранируются плотной древесно-кустарниковой растительностью, а пункт 10 такого экрана лишен. С учетом всех перечисленных обстоятельств о результатах трансплантационного эксперимента в пунктах 9, 10 и 11 можно сказать следующее.

9 - «Клёны». Летом в этом пункте фиксируются высокий $K_{\kappa}$ у $\mathrm{Pb}(4,40)$, это результат конвективного переноса к ней воздушных масс, загрязненных автотранспортными выхлопами. Зимой химические элементы в существенных количествах в талломах трансплантатов пункта 9 не накапливаются. В холодное время года конвективная миграция воздушных масс от шоссе вверх по Днепровскому склону не происходит.

10 - верхняя часть Днепровского склона за участком «Сосны». Летом в этом пункте экспозиции загрязнение, согласно данным эксперимента, достигает средних уровней для территории НБС. Зимой же это один из наиболее загрязненных пунктов трансплантации. Наиболее высокие $K$ отмечаются y Al $(2,5), \mathrm{Fe}(5,7), \mathrm{Na}(6,1), \mathrm{Ba}(2,2), \mathrm{Cu}(3,9), \mathrm{Co}(3,9)$. Воздушные массы пункта 10 , судя по всему, имеют комплексное загрязнение, в них присутствуют компоненты выбросов предприятий Левого берега, автомобильных выхлопов шоссе, частички терригенной пыли, приносимой восточными ветрами.

11 - подножье Днепровского склона, около ограды, крайняя северо-западная оконечность НБС. Этот пункт загрязняется непосредственно выбросами автотранспорта, который движется по транспортной развязке на въезде на мост им. Патона. Пункт не защищен от влияния загрязненных воздушных масс ни растительностью, ни рельефом. Летом в пункте 11 наблюдаются относительно высокие $K_{\kappa}$ у $\mathrm{Pb}(4,9), \mathrm{Cu}$ $(3,7)$ и $\mathrm{Ni}(4,8)$, которые типичны для мелкодисперсных аэрозолей автотранспортного выброса. Зимой сохраняется относительно высокий $K_{\kappa}$ у $\mathrm{Pb}(4,0)$. В годичном разрезе, когда влияние сезонных микроклиматических флуктуаций перестает сказываться на формировании уровней загрязнения приземной атмосферы, пункт 11 может быть охарактеризован как один из самых загрязненных: высокие значения $K$ наблюдаются для $\mathrm{Mg}(2,9), \mathrm{Fe}(3,0), \mathrm{Mn}(3,4), \mathrm{Zn}(5,6)$, $\mathrm{Sr}(2,6), \mathrm{Pb}(3,3), \mathrm{Cr}(4,7), \mathrm{Cd}(6,2)$. Все эти микроэлементы в той или иной форме поступают в приземную атмосферу в результате работы автомобильного транспорта, причем не только из-за выхлопа (Mg, Zn, $\mathrm{Pb}, \mathrm{Sr})$, но и из-за истирания резины автомобильных шин $(\mathrm{Cd})$ и движущихся частей моторов ( $\mathrm{Fe}, \mathrm{Mn}, \mathrm{Cr})$.

12 - «Хоздвор». По техническим причинам трансплантационный эксперимент на пункте 12 был проведен только в зимний период. Этот пункт расположен в балке, по которой проходит ул. Тимирязевская, в пределах административно-хозяйственной части НБС, за гаражами. Техногенное влияние на нее возможно от автотранспортного хозяйства НБС. Массы воздуха, загрязненные выбросами автомобильного транспорта, движущегося по Надднепрянскому шоссе, пункта 12 не достигают; выбросы промзоны «Выдубечи» для него также мало актуальны. За холодный период 2013-2014 гг. заметного накопления химических элементов в слоевищах экспонированной $H$. physodes в пункте 12 не произошло. Это свидетельствует о том, что техногенные выбросы хоздвора НБС НАНУ существенной роли в загрязнении территории сада не играют.

\section{Выводы}

- Эксперимент по изучению атмосферного загрязнения методом тестовых трансплантатов с использованием эпифитного лишайника Hypogymia physodes, проведенный в 12 пунктах наблюдения (экспонирования) на территории НБС НАН Украины в 2013-2014 гг., подтвердил высокую эффективность этого биоиндикационного способа контроля атмосферного загрязнения воздушной среды.

- Трансплантационный эксперимент показал, что основными источниками и причинами атмосферного загрязнения территории НБС являются: а) промышленная зона «Выдубечи» с ТЭЦ-5; б) Надднепрянское шоссе и его часть - транспортная развязка на въезде на мост им. Патона; в) воздушные массы, несущие в себе «общегородскую» атмотехногенную нагрузку, то есть загрязненные всей суммой техногенных объектов мегаполиса (особенно те из них, которые формируются на Левом берегу); г) подъем терригенный пыли. Деятельность хозяйственного двора заметного влияния на загрязнение территории НБС не оказывает

- Наиболее существенное техногенное загрязнение приземной атмосферы наблюдается в: а) крайних южном и северо-восточном пунктах экспонирования лишайников, которые размещаются в нижней части и у подножья коренного Днепровского склона; б) в северо-восточном пункте, расположенном на бровке Днепровского склона, который хорошо обдувается ветрами восточных румбов; в) в южной части НБС в зоне влияния шлейфа выбросов ТЭЦ-5. В целом, пространственное распределение атмосферных загряз- 
нителей по территории НБС зависит от положения пункта наблюдения по отношению к главным источникам выбросов, от особенностей рельефа (включая искусственный) территории сада и от пространственной структуры древесно-кустарникового покрова, являющегося аэродинамическим барьером на пути движения загрязненных воздушных масс около земной поверхности.

- Наиболее важными сезонными закономерностями накопления химических элементов в лишайниках-трансплантатах являются такие. Ванадий (маркер аэрозольных выбросов ТЭЦ) больше всего накапливается в холодный период экспозиции, хотя и в лишайниках с годичным периодом экспозиции его содержание высоко. Сера (маркер газовых выбросов ТЭЦ) очень сильно накапливается в лишайниках сразу после начала экспонирования, в теплый период года, а в дальнейшем ее содержание в слоевищах меняется незначительно. То есть динамическое равновесие между содержанием серы в воздухе и слоевище лишайника-трансплантата достигается уже за первые полгода экспозиции. Медь практически не на- капливается зимой, во многих случаях даже вымывается из слоевищ трансплантатов. Но она хорошо аккумулируется в них в летний период экспонирования. Вероятно, в этом случае важную роль играет физиологический фактор поглощения и удержания мелких аэрозолей, содержащих медь, талломом. За год медь устойчиво накапливается только в пунктах, подверженных значительному автотранспортному и теплоэнергетическому загрязнению. Слабо поглощаются или вообще не накапливаются в трансплантатах биогенные калий, фосфор, марганец - как по полугодиям, так и за год. С незначительными сезонными вариациями поглощается свинец (маркер автотранспортного загрязнения). За год его содержание в слоевищах значительно возрастает. Накопление стронция (в данном эксперименте - маркер терригенной пыли) относительно заметно в отдельных пунктах только за годичный период экспонирования. В целом сезонная картина накопления химических элементов в слоевищах трансплантатов $H$. physodes имеет существенные различия в теплое и холодное полугодия экспонирования.

\section{Литература}

\section{Список русскоязычной литературы}

1. Авессаломова ИА. Геохимические показатели при изучении ландшафтов. М.: Изд-во МГУ; 1987.

2. Бязров ЛГ. Лишайники в экологическом мониторинге. М.: Научный мир; 2002.

3. Ковалевский АЛ. Биогеохимия растений. Новосибирск: Наука; 1991.

4. Михайлова ИН, Шарунова ИП. Динамика аккумуляции тяжелых металлов в талломах эпифитного лишайника Hypogymnia physodes. Экология. 2008;(5):366-72.

5. Сидорович ЕА, Алехно АИ, Бусько ЕГ и соавт. Экологический мониторинг лесных ландшафтов Белоруссии. Минск: Наука и техника; 1988.

\section{Общий список литературы/Reference List}

1. Avessalomova IA. Geokhimitheskie Pokazateli pri Izuchenii Landshaftov. [Geochemical Indicators in Landscape Studies]. Moscow: MGU; 1987. (In Russ.)

2. Biazrov LG. Lishayniki v Ekologicheskom Monitoringt. [Lichens in Environmental Monitoring]. Moscow: Nauchyi Mir; 2002. (In Russ.)

3. Kovalevskiy AL. Biogeokhimiya Rastenii. [Plants Biogeochemistry]. Novosibirsk: Nauka: 1991. (In Russ.)

4. Mikhailova IN, Sharunova IP. [Dynamics of accumulation of heavy metals in the thalli of the epiphytic lichens Hypogymnia physodes]. Ekologiya. 2008;(5):366-72. (In Russ.)

5. Sidorovich YeA, Alekhno AI, Bus'ko YeG, Iodo AN, Motyl' MM, Yurkevich ID. Ekologicheskiy Monitoring Lesnykh Landshaftov Belorussii. [Environmental Monitoring of the Belarusian Forest Landscapes]. Minsk: Nauka i Tekhnika; 1988. (In Russ.)

6. Brown DH. The location of mineral elements in lichens: implications for metabolism. Bibliotheca Lichenologica. 1987;25(6):361-75.

7. Gailey FAY, Lloyd OL. Methodological investigations into low technology monitoring of atmospheric metal pollution. Environ Pollution Ser B.1986;12(1,2):41-59,61-74.

8. Nash III TH. Nutrients, elemental accumulation and mineral cycling. In: Nash III TH, ed. Lichen Biology Cambridge: Cambridge University Press, 1996; p. 136-53.

9. Palomäki V, Tynnyrinen S, Holopainen T. Lichen transplantation in monitoring fluoride and sulfur deposition in the surroundigs of a fertilizer plant and strip mine at Siilinjärvi. Ann Bot Fennici. 1992;29:25-34.

10. Pilegaard K. Heavy metals in bulk precipitation and transplanted Hypogymnia physodes and Diocranowesia cirrata in the vicinity of a Danish steelwork. Water Air Soil Pollution. 1979;11(1):77-91.

11. Steinnes E, Krog H. Mercury, arsenic and selenium fall-out from an industrial complex studied by means of lichen transplants. Oikos. 1977;28(2):160-64. 